\title{
Intelligent Management of High-Technology Equipment for the Manufacture of Concrete and Ceramic Materials and Products
}

\author{
Konstantin Galitskov* \\ Samara State Technical University, 194 Molodogvardeyskaya St., 443001, Samara, Russia
}

\begin{abstract}
The article describes the strategy of effective management of improving technological processes of the concrete and ceramic materials and products manufacture that consists of creating intelligent control systems, in which the developed mathematical models of these processes and the algorithms of the forecast characteristics of the produced materials and products are used (in the setting of essential nonstationarity of these processes as control objects).
\end{abstract}

\section{Introduction}

Concrete and ceramic materials and products (CCMPs) widely used in modern construction (concrete beams, ceilings, cellular concrete products, ceramic bricks, expanded clay, etc.) are mainly characterized by their strength $\mathrm{R}$ and density $\rho$. These features are formed in the process of manufacture and depend on many factors: mineralogical and rheological characteristics of raw materials, formulation and technology of mixture production, modes of the subsequent technological procedures (molding, drying, heating, etc.), as well as on technological limitations and technical characteristics of the equipment used: vibroplatforms, screw presses for forming raw ceramic bricks, rotating or tunnel kilns, autoclaves, etc.

Sustainable production of CCMPs (Figure 1) with the minimum allowable deviation of their R and (or) $\rho$ from the set values is possible while ensuring efficient management of the specified equipment and technological processes. The difficulties in achieving the desired results can be explained by the following reasons. First, it is due to the inadequate use of control actions potentially available in the equipment (for example, in a rotary kiln, as a rule, rotation speed is not adjustable $\omega_{\Pi \text { II }}$, the same for a screw press and the depth of rarefaction $\mathrm{P}_{\mathrm{B}}$ in a vacuum chamber, etc.). Secondly, it is due to limited possibilities of the applied actuating devices. For example, the vibration exciters used (unbalanced, as a rule) have no option of changing the amplitude A of the oscillations during the vibration process. In addition, there is the complexity of monitoring individual process parameters of the product or the equipment.

\footnotetext{
*Corresponding author: ksgal@yandex.ru
} 


\begin{tabular}{|c|c|c|c|c|c|}
\hline \multirow{2}{*}{ Manufacture types } & \multicolumn{5}{|c|}{ MAIN TECHNOLOGICAL PROCESSES } \\
\hline & $\begin{array}{l}\text { Preparation of concrete } \\
\text { (or clay) mix }\end{array}$ & \multicolumn{2}{|c|}{ Forming of raw products } & \multicolumn{2}{|c|}{ Heat treatment } \\
\hline $\begin{array}{l}\text { MOLDED CONCRETE } \\
\text { PRODUCTS }\end{array}$ & $\begin{array}{l}\text { Concrete mixing } \\
\text { unit }\end{array}$ & $\begin{array}{l}\text { Vibro } \\
\text { concre }\end{array}$ & insion of & \multicolumn{2}{|c|}{$\begin{array}{l}\text { Heat and moisture } \\
\text { product treatment }\end{array}$} \\
\hline $\begin{array}{l}\text { CELLULAR } \\
\text { CONCRETE } \\
\text { PRODUCTS }\end{array}$ & $\begin{array}{l}\text { Cellular concrete } \\
\text { mix manufacture }\end{array}$ & $\begin{array}{l}\text { ncrete } \\
\text { owout }\end{array}$ & String cutting & \multicolumn{2}{|c|}{ Autoclaving } \\
\hline CERAMIC BRICKS & Clay mixer & \multicolumn{2}{|c|}{$\begin{array}{c}\text { Forming in screw } \\
\text { press }\end{array}$} & Drying & Heating \\
\hline EXPANDED CLAY & Clay mixer & \multicolumn{2}{|c|}{$\begin{array}{c}\text { Forming of raw } \\
\text { material }\end{array}$} & \multicolumn{2}{|c|}{$\begin{array}{c}\text { Drying and heating in } \\
\text { a rotary kiln }\end{array}$} \\
\hline
\end{tabular}

Fig. 1. Generalized structure of producing CCMPs

Substantial nonstationarity and non-linear nature of the object parameters, caused by the significant variation in the characteristics of raw materials, limited power of the power converters, and the complex interrelationships of the individual executive systems through a generalized control object, serve as obstacles in solving these critical tasks.

The article considers the specifics of using the artificial intelligence elements for solving problems of managing technological complexes of high-tech equipment for production of CCMPs with specified strength or density, exemplified by the manufacture of reinforced concrete products, ceramic bricks, expanded clay and cellular concrete products.

\section{Materials and methods}

The problem of creating high-technology equipment for CCMP production can be split into two challenges (Figure 2). The first is related to the improvement of technological process management. The second challenge is about developing and designing new construction machines targeted at the implementation of new or more advanced technologies and creating control systems for these machines. For the practical implementation of effective production management, mathematical models of the main technological processes (Figure 1), as management objects, have been developed [1-4].

A distinctive feature of the developed mathematical models of controlled objects is the presence of $\mathrm{R}$ and $\rho$ in the $\bar{x}$ vector of output coordinates, which are structurally and analytically related to the observed coordinates of the controlled objects. This allows the development of digital monitoring for R and $\rho$, and further - of the devices for adjusting automatic control systems (ACS) for technological processes (Figure 3). 


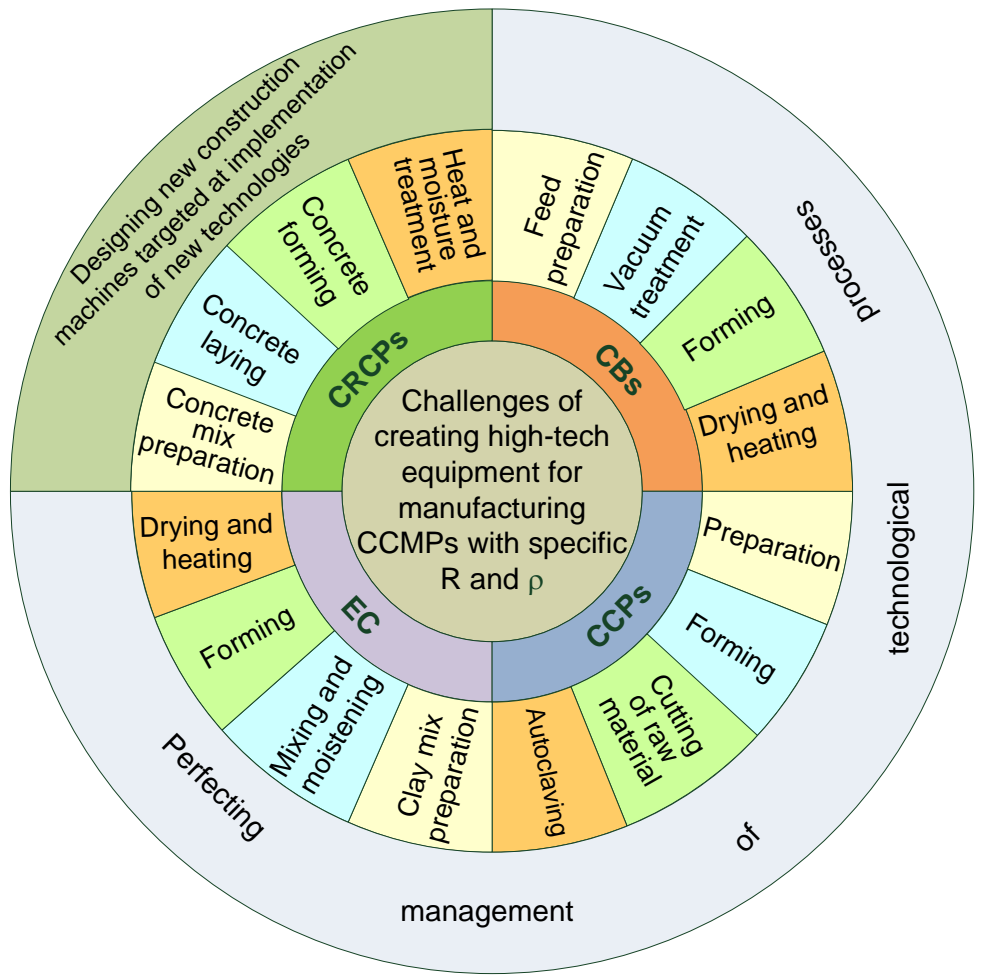

Fig. 2. Challenges of automated production of CCMPs with specified quality indicators; CRCPs concrete and reinforced concrete products; CBs - ceramic bricks; CCPs - cellular concrete products; EC - expanded clay

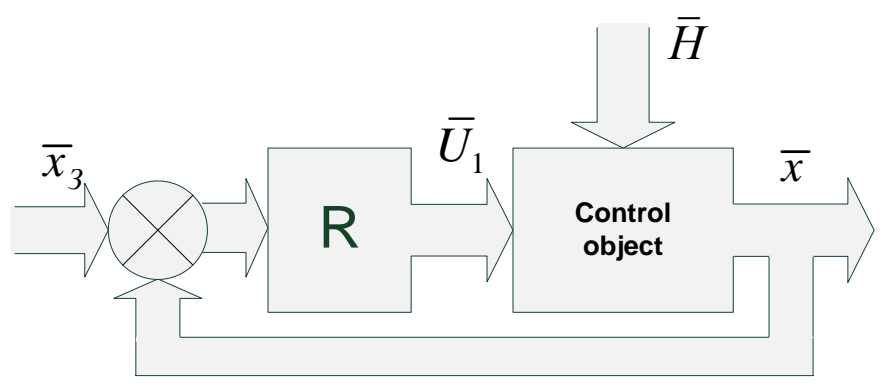

Fig. 3. Structure of the ACS for a technological process; R - ACS regulator

The analysis of the performed studies on mathematical modeling shows that they are multidimensional objects with distributed parameters that (due to the specific features of the technology of CCMPs manufacture) are essentially variable. Studies show that the equipment design significantly affects the object dynamics. Thus, vibrocompaction of a concrete mixture in a mold by a two-shaft vibroexciter is a high-speed fast-growing process mainly determined by the dynamics of electromagnetic and electromechanical processes in asynchronous engines of unbalanced exciters. Moreover, the processes of changing thermal field parameters of the expanded clay in a rotary kiln are considerably inertial. The dynamics of separate channels and interchannel connections in the object can here be described with sufficient accuracy by a successive combination of aperiodic and delay elements with a significant delay time. It has been discovered that the interconnections 
between separate channels are determined by both the technology features and the executive electric drives.

\section{Results}

To solve the task of producing CCMPs of a given strength (or density), taking into consideration the above-mentioned features of the controlled objects, we find it necessary to use artificial intelligence elements in automatic control systems of technological processes. Two processes can serve as typical examples - the process of heating expanded clay in a rotary kiln and the process of forming a ceramic brick in a screw vacuum press.

In the first example, it is proposed to measure the temperature of expanded clay in three sections $\mathrm{A}, \mathrm{C}$ and $\mathrm{F}$ along the axis of rotation for control efficiency. In addition, three kiln control actions are implemented (for rotational speed, volumetric thermal power of the burner, and consumption of the raw material being fed). The functional dependences of the predicted strength of expanded clay from the elements of the vector of control actions and from non-stationary disturbances are developed.

To solve the inverse problem, namely, the tracing of the clay heating curve, taking into account the parameters of the raw material and technical characteristics of the kiln in threedimensional space, the coordinates of which are the kiln temperature in the distinctive sections $\mathrm{A}, \mathrm{C}$ and $\mathrm{F}$, the computational algorithms are generated. They help to build a temperature-strength characteristic of heating expanded clay [5]. This curve is digitized according to the expanded clay predicted strength (Figure 4).

The problem of production of ceramic bricks, when one of the important steps - the process of forming raw materials in a vacuum press - is automated, is solved in a similar way. As studies show [6], the most important technological parameter here is the rate of change of the tangential deformations on the wall of the forming element. This value is immeasurable, so a digital monitor is used here. The connection of predicted brick strength with three controlled axes (degree of vacuum processing $\mathrm{P}_{\mathrm{B}}$, raw material moisture content $\mathrm{W}$ and rotation speed of the screw $\omega \amalg)$ is represented by constant value of brick strength of four grades (Figure 5).

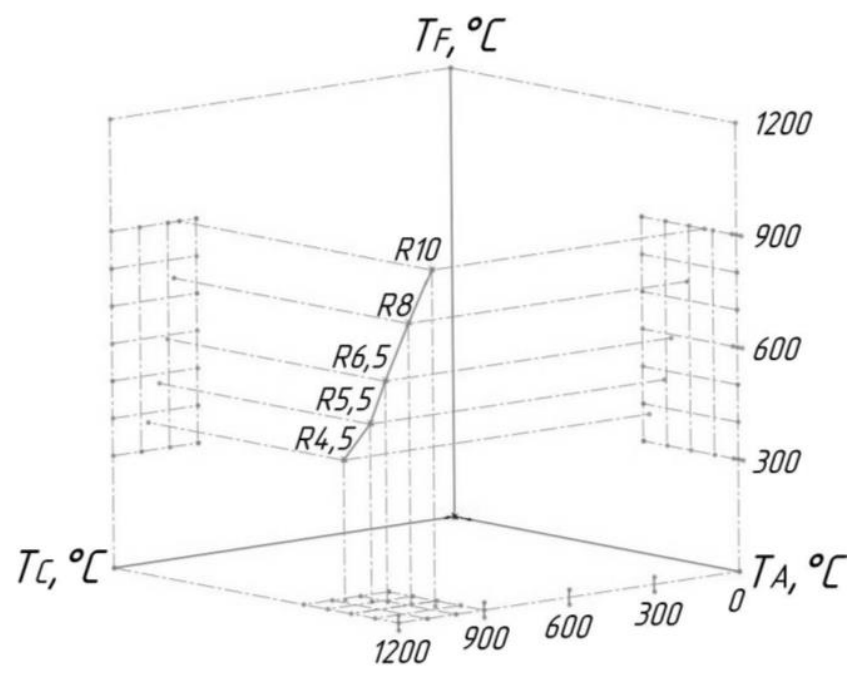

Fig. 4. Temperature-strength characteristics of heating expanded clay 


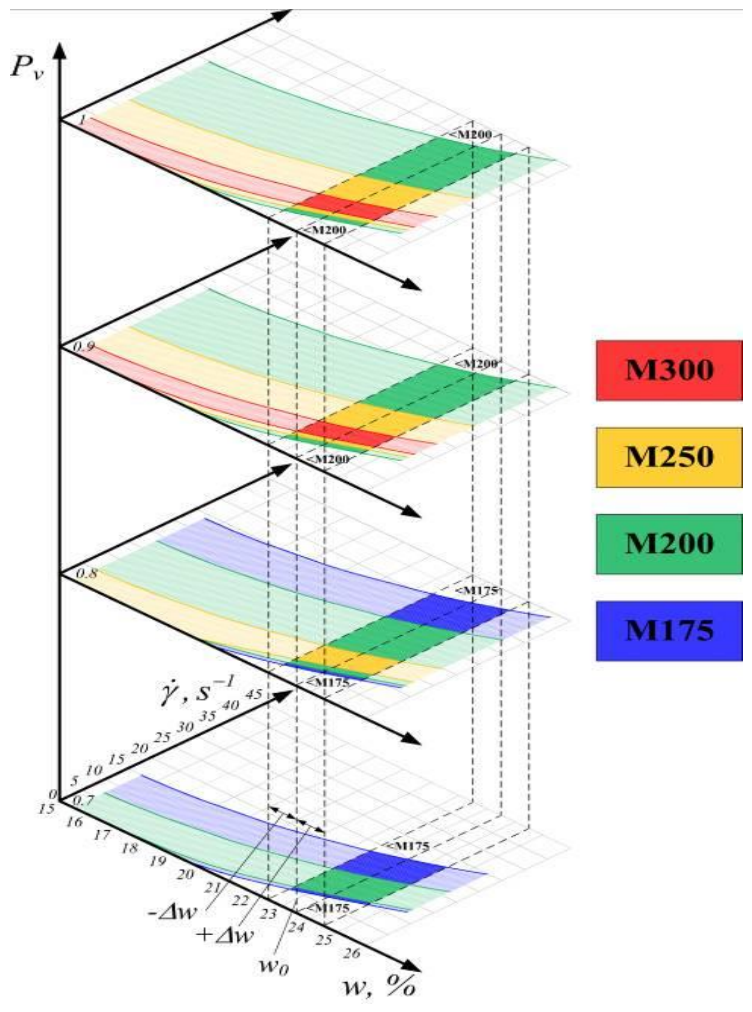

Fig. 5. $M$ set of brick grades in the space of technological parameters of the ceramic mixture forming process

\section{Discussions}

Creating a knowledge bank of mathematical models of technological processes for CCMP production, as well as that of the projected characteristics, in particular, the $\mathrm{R}$ strength of manufactured products, creating a database of raw material characteristics and equipment features make it possible to use this intellectual information for effective management of the technologies in question [7]. In this case, automatic production management includes the following stages: the first is the definition of the control area (for example, heating of expanded clay), the second is the evaluation of the possibility of producing expanded clay with a given $\mathrm{R}$ (or $\rho$ ) from the source raw material in the kiln under consideration. The third stage consists in selecting the values of the elements $\left(T_{A}, T_{C}\right.$ and $\left.T_{F}\right)$ in the vector of the reference coordinates $\bar{x}_{3}$, adapted to the production with specified quality parameters.

\section{Conclusions}

The article states that the design and development of high-technology equipment for production of CCMPs is greatly influenced by artificial intelligence elements installed in the systems controlling technological processes of these production units. These elements are based on the created bank of mathematical models and algorithms for determining the predictive characteristics of the materials and products manufactured. 


\section{References}

1. S. Galitskov, M. Nazarov, K. Galitskov, IOP Conference Series: Earth and Environmental Science, 90, 012131 (2017)

2. S.Ya. Galitskov, K.S. Galitskov, O.V. Samokhvalov, A.S. Fadeev, Scientific Review, 7, $11(2015)$

3. S.Ya. Galitskov, K.S. Galitskov, A.V. Baskakov, Automation of Compacting Concrete Mix in a Mold by Two-Shaft Vibration Exciters (Samara: SSUACE, 2012)

4. S.Ya. Galitskov, K.S. Galitskov, M.A. Nazarov, Industrial and Civil Construction, 3, 5 (2014)

5. K.S. Galitskov, O.V. Samokhvalov, Industrial and Civil Construction, 9, 4 (2015)

6. S. Galitskov, M. Nazarov, K. Galitskov, MATEC Web of Conferences, 86, 04010 (2016)

7. S.Ya. Galitskov, K.S. Galitskov, M.A. Nazarov, Scientific Review, 14, 6 (2015) 